\title{
Associations between firearm and suicide rates: a replication of Kleck (2021)
}

Tyler J Lane

\section{Affiliations}

School of Public Health and Preventive Medicine, Monash University, Melbourne, Australia Cancer Council Victoria, Melbourne, Australia

Email: tyler.lane@monash.edu

Twitter: @DrTLane

ORCiD: https://orcid.org/0000-0001-6089-1827

Word count: 3,984 


\section{Abstract}

\section{Objective}

Using data from $n=194$ nation-states, Kleck (2021) found that firearm availability was only associated with firearm suicide rates, but not total or non-firearm suicides. He thus concluded that while firearm availability influences how people commit suicide, it does not affect total numbers. However, the study contains numerous logical and methodological issues and is at odds with the evidence base. Therefore, I attempt to reproduce the original results.

\section{Method}

I reproduce the original study's methods: ordinary least squares regression, weighted by the square root of the population, with log-transformed suicide rates and three separate firearm availability measures: global estimates from the Small Arms Survey, proportion of suicides committed with firearms, and an European Union survey of firearm ownership. I also test several methodological variations and include US suicide data.

\section{Results}

In contrast to Kleck, global analyses with Small Arms Survey data found a significant and positive association between firearm availability and total suicides, as did US analyses. Analyses with other firearm availability measures comported with the original study, finding no association.

\section{Conclusion}

The main result in Kleck (2021) failed to reproduce, finding a significant association between firearm availability and suicide rates, as did US analyses. While reproductions of Kleck's other analyses continued to show no association, they were based on unreliable methods. I 
therefore reject Kleck's conclusion that that firearm availability does not influence suicide rates.

\section{Highlights}

- Using data global data, I find firearm availability is positively associated with suicide rates.

- I identify serious flaws in the logic and methods of Kleck (2021) and an earlier review.

- For transparency, data and code have been archived on a public repository. 


\section{Introduction}

Using data from 194 nations and sovereign territories, Kleck (2021) conducted three separate analyses of the association between firearm avaialbility and suicide rates. Each found that firearms are only significantly associated with rates of firearm suicide, but not total or nonfirearm suicides. Summarising his results, he writes, "Availability of firearms appears to affect how people kill themselves, but not how many people do so,” (Kleck, 2021, pp. 7-8)

This conclusion is unjustified. If firearms only influence how people commit suicide, the positive association between firearm availability and firearm suicides should be paired with a negative association with non-firearm suicides. ${ }^{1}$ Further, Kleck's findings are internally inconsistent; if firearm availability only influences firearm suicide rates, it must also influence non-firearm suicide rates (indicating method substitution) or total suicides (indicating an increase in overall rates). While statistical analyses cannot always distinguish signal from noise, it is incumbent on researchers to acknowledged when their findings are incomplete and draw less certain conclusions.

Kleck also dismisses arguments that method substitution could result in more suicides due to differences in lethality, claiming that, based on his own analysis of US suicide data (Kleck, 2018), firearm suicide attempts are not significantly more lethal than hanging, the second most common suicide method. However, numerous other studies and systematic reviews find that firearm suicide attempts are in fact deadlier (Cai et al., 2022; Elnour \& Harrison, 2008; Shenassa et al., 2003), and his own data do not support this claim. ${ }^{2}$ But the most glaring issue

\footnotetext{
${ }^{1}$ One of the analyses does find an association between firearm availability and non-firearm suicide rates, though it is based on unreliable methods that are prone to spurious results. See below for a discussion using the proportion of suicides commited with a gun as a proxy for firearm availability when suicide is the outcome. ${ }^{2}$ Kleck cites his earlier review (Kleck, 2019), which itself cites his earlier chapter (Kleck, 2018). In this, he uses CDC suicide and suicide attempt data to argue that lethality of firearm and hanging/suffocation suicide attempts are not significantly different because "there is heavy overlap between the confidence intervals surrounding the
} 
is this argument falls victim to the base-rate fallacy: Kleck uses completed suicides as his denominator rather than suicide attempts. His own prior analysis (Kleck, 2018) of CDC data suggests that in the US, while firearm and hanging/suffocation suicide attemps accounted for the majority of attempts $(52.5 \%$ and $24.0 \%)$ but less than $10 \%$ of completions $(5.8 \%$ and 2.9\%). Conversely, poisonings accounted for nearly two-thirds of suicide attempts (63.9\%) but just $2.5 \%$ of completions. This means that even if a small share of suicide attempts substituted a firearm for poison, the number of attempts would stay the same while completed suicides increase.

\section{Analytical issues in Kleck (2021)}

In his earlier review, Kleck argues the evidence finding a link between firearm availability and suicides is plauged by three major methodological problems: "(1) use of invalid or contaminated measures of gun ownership prevalence, (2) the use of needlessly small samples of macro-level units, and (3) the failure to control any significant number of confounding variables" (Kleck, 2019, p. 937). Yet all of the analyses in Kleck (2021) uses at least one of these. While it is debatable whether all are in fact major problems, this shows is an inconsistent methodological standard.

The methodological problems themselves warrant some discussion. The first refers to the proportion of suicides comitted with a gun (PSG). While PSG is highly correlated with firearm ownership (National Research Council, 2005), it becomes unreliable when the outcome is suicide because the same data appear in the dependent and independent variables,

estimates" (p. 320). However, this is an inappropriate way to make statistical comparisons. Using a Poisson regression with the data in Kleck (2018, Table 17.3), I compared lethality of firearm (258,386 deaths, 308,623 attempts, $83.7 \%$ lethal) and hanging/suffocation suicide attempts (118,072 deaths, 154,013 attempts, 76.7\% lethal). Firearm suicide attempts are $8.8 \%$ more deadly, or conversely, hanging/suffocation attempts are $36.0 \%$ more surivavable (both $p<0.001$ ). 
resulting in circularity and spurious associations (Duggan, 1999; National Research Council, 2005). Kleck himself wrote that "PSG to measure gun prevalence in an analysis of suicide rates is inappropriate" and noted that when using composite measures of firearm availability, he "took care to omit PSG" (Kleck, 2019, p. 937). Yet in Kleck (2021), he justified his own use of PSG by arguing that it "is available for 194 nations, allowing generalization of findings to the world community of nations," (p. 7). This fails to address the underlying problem that, no matter the sample size, such analyses are inherently unreliable, nor does it explain why it was previously deemed "inappropriate," but acceptable for this study. Kleck had previously been unforgiving of researchers who justify their use of flawed methods on the grounds of availability, writing that "such an argument is disengenuous since the authors did not have to use such units," (Kleck, 2019, p. 942).

The second problem, "needlessly small samples of macro-level units," is attributed to the sensitivity of results to single cases and limited the ability to add control variables. This point is reiterated in Kleck (2021), where he writes, "Although a handful of cross-national studies have been done, they have all been based on small (14-36 countries), unrepresentative samples, almost entirely limited to highly developed nations" (p. 2). Yet one of the analyses Kleck (2021) is of the European Union, which at the time had only 28 members. Indeed, the above quote that "such an argument is disengenuous since the authors did not have to use such units" specifically referred to researchers using small samples.

Kleck devotes most of his review to the third problem, a lack of control for confounders, which he describes "Probably the most consequential flaw in research in this area is the neartotal failure to adequately control for confounding variables" (Kleck, 2019, p. 942). Yet none of the analyses in Kleck (2021) used any statistical controls. His justification was that the effect was near zero and his review did not identify any potential confounders that could 
undo a potential suppression effect. However, as far as can be determined, these potential confounders originate entirely from US-based studies, which can hardly be thought to generalise globally. For instance, two of the confounders are percent of the population that is African American and whether the state is in the Western census region. But most troublingly, this suggests that Kleck would modify his analyses depending on the results, in this case only if there were a significant association between firearm availability and suicide.

Taken together, Kleck's decision to conduct and report a study using methods he previously identified as "major problems," but which nevertheless concur with his previous conclusions, is indicative of researcher degrees of freedom or $p$-hacking (Simmons et al., 2011). Such practices are one of the main drivers of the replication crisis (Bishop, 2019) and raise serious questions about the reliability of his findings.

\section{Flawed review of the evidence}

Kleck points to his own review (Kleck, 2019) to claim his findings are consistent with the evidence base. However, this review contains numerous flaws, which may explain why its conclusions are in stark contrast with other reviews on this topic (Anglemyer et al., 2014; Miller et al., 2016; RAND Corporation, 2018). The most serious flaw is that Kleck refers to his review as "systematic," even though it lacks the defining features of "systematic and explicit methods to identify, select, and critically appraise relevant research," (Moher et al., 2009 , p. 1). Indeed, the review contains no methods at all. The consequences are evident, as numerous relevant studies are excluded, nearly all of which find a significant association between firearm availability and suicide (Anestis \& Houtsma, 2018; Briggs \& Tabarrok, 2014; Crowder \& Kemmelmeier, 2014; Duggan, 1999; Hamilton \& Kposowa, 2015; Hemenway \& Miller, 2002; Kposowa, 2013; Miller et al., 2013; Opoliner et al., 2014; Phillips, 2013; Reisch et al., 2013; Smith \& Kawachi, 2014). This review also misreports the 
findings of studies that were included. For instance, Killias (1993) is incorrectly recorded as finding found no association between firearm availability and total suicide rates.

The review's findings are summarised as such:

"All prior studies that documented controlling for more than two significant confounders and used an uncontaminated gun measure [not PSG] found that gun levels are significantly related to firearms suicide rates but found no association with total suicide rates," (2019, p. 948).

This is inaccurate, which is surprising because the only studies that meet these criteria are two of Kleck's own. For instance, from Kleck (1991): "The findings indicate that gun ownership appears to have no effect on rates of total, gun, or nongun suicide" (pp. 255-256). Kleck \& Patterson (1993) did find that firearm availability was significantly associated with both total and firearm suicides in its main analyses, though Kleck's review emphasises separate analyses that assumed endogeneity (suicide rates influence firearm ownership), in which neither association was significant. It unclear why Kleck's review highlights the latter analysis, since Kleck \& Patterson (1993) wrote "No effect of suicide and fatal gun accident rates on gun acquisition was expected," (Kleck \& Patterson, 1993, pp. 256-257). Kleck’s review also reports that Kleck \& Patterson (1993) found that the association between firearm availability and total suicides became non-significant when the used crude rather than logtransformed suicide rates. However, these additional analyses appear nowhere in the original paper and were seemingly conducted for the review published 26 years later.

Not only does this raise questions about the accuracy of the review, since Kleck has not even accurately summarised his own studies, the failure to consistently detect an association between firearm availability and firearm suicide raises further questions about the reliability 
of his studies. The National Research Council noted that "the body of ecological studies has firmly established that firearm access is positively associated with gun suicide" (2005, p. 164).

Study aims aims

Given these concerns, I reproduce the study in Kleck (2021). In addition, I attempt a replication with analytical modifications and US state data. 


\section{Materials and methods}

\section{Data}

Data sources are listed Table 1. Where possible, the reproduction uses the exact data as described in Kleck (2021). However, while Kleck matched 194 countries for global analyses, I was able to match 203 nations-states. The reason for this discrepancy are unclear.

Analytical subgroups included age, sex, and in the US, ethnicity. Age groups were 15-49 years, 50-69 years, and 70+ years, which were the most sizeable and comprehensive categories available in Global Burden of Disease data. CDC data were extracted along the same categories for consistency. Ethnic groups in US data were White, Black, Asian, and Native American, the broader categories provided by the CDC.

CDC WONDER, the source for US suicide data, suppresses cells smaller than 10, which affected some demographic subgroups. To ensure coverage for as many subgroups as possible and generate more stable estimates, US suicide data are amalgamated from the years 2010-2019. 
Table 1. Data sources

\begin{tabular}{|c|c|c|c|c|c|c|c|}
\hline \multirow[t]{2}{*}{ Analysis } & \multicolumn{3}{|l|}{ Suicide data } & \multicolumn{3}{|l|}{ Firearm availability data } & \multirow[t]{2}{*}{ Units } \\
\hline & Source & Codes & Year(s) & Source & Operationalisation & Year(s) & \\
\hline \multirow[t]{2}{*}{ Global } & \multirow{3}{*}{$\begin{array}{l}\text { Global Burden of } \\
\text { Disease (GBD) } \\
\text { Collaborative Network } \\
(2020)\end{array}$} & \multirow{3}{*}{$\begin{array}{l}\text { C.3.1: all-cause self- } \\
\text { harm } \\
\text { C.3.1.1: self-harm by } \\
\text { firearm } \\
\text { C.3.1.2: self-harm by } \\
\text { other specified means }\end{array}$} & \multirow[t]{3}{*}{2017} & $\begin{array}{l}\text { Small Arms Survey (Karp, } \\
\text { 2018) }\end{array}$ & $\begin{array}{l}\text { Firearms per } 100 \\
\text { population }\end{array}$ & 2017 & \multirow[t]{2}{*}{$\begin{array}{l}203 \text { nations- } \\
\text { states }\end{array}$} \\
\hline & & & & $\begin{array}{l}\text { Global Burden of Disease } \\
\text { (GBD) Collaborative Network } \\
(2020)\end{array}$ & $\begin{array}{l}\text { Proportion of Suicides } \\
\text { committed with Guns } \\
\text { (PSG) }\end{array}$ & 2017 & \\
\hline $\begin{array}{l}\text { European } \\
\text { Union }\end{array}$ & & & & $\begin{array}{l}\text { Firearms in the European } \\
\text { Union survey (European } \\
\text { Commission, 2013) }\end{array}$ & $\begin{array}{l}\text { Firearm ownership } \\
\text { rate }\end{array}$ & 2013 & $\begin{array}{l}28 \mathrm{EU} \text { member } \\
\text { states }\end{array}$ \\
\hline $\begin{array}{l}\text { United } \\
\text { States }\end{array}$ & $\begin{array}{l}\text { CDC's Wide-ranging } \\
\text { Online Data for } \\
\text { Epidemiological } \\
\text { Research (WONDER) } \\
\text { (Centers for Disease } \\
\text { Control and } \\
\text { Prevention, 2021) } \\
\end{array}$ & $\begin{array}{l}\text { X60-X84: intentional } \\
\text { self-harm } \\
\text { X72-X74: firearm } \\
\text { suicides } \\
\text { X70-X71, X75-X84: } \\
\text { all other suicide } \\
\text { methods }\end{array}$ & $2010-19$ & $\begin{array}{l}\text { YouGov survey (Kalesan et al., } \\
\text { 2016) }\end{array}$ & $\begin{array}{l}\text { Firearm ownership } \\
\text { rate }\end{array}$ & 2013 & $\begin{array}{l}50 \text { states and } \\
\text { the District of } \\
\text { Columbia }\end{array}$ \\
\hline
\end{tabular}




\section{Analysis}

The reproduction of Kleck (2021) uses the exact same methods: Ordinary Least Squares regression weighted by the square root of the population to test the association between each firearm measure and category of suicide (total, firearm, and non-firearm). Suicide rates are log-transformed, though not for the purpose of normalising the skewed distribution, the mistaken reason provided by Kleck. While model residuals should be normally distributed, it is unnecessary for regression variables to be so (Gelman et al., 2020).

Additional analyses convert crude firearm rates to rank and z-scores to account for the extreme United States outlier at 120 per 100 population (the next highest firearm rate is Yemen at 53 per 100 population), check robustness of results, and better visualise associations. Z-transformations of independent variables can give a better indication of effect magnitudes because they present associations in terms of standard deviation changes in the exposure of interest (Gelman et al., 2020); crude and rank-transformed firearm availability present artificially small associations, where coefficients are based on either a single unit increase in firearms per 100 persons or a single percentage point increase in firearm ownership rates. Effect sizes are conveyed with r-squared and the following classifications: "Recommended Minimum Effect Size/RMPE"3 = 0.04, "moderate" = 0.25, and "strong" = 0.64 (Ferguson, 2009).

All analyses were conducted in R using RStudio (R Core Team, 2021; RStudio Team, 2020) with the following packages: broom (Robinson \& Hayes, 2020), ggpubr (Kassambara, 2020), janitor (Firke, 2020), magrittr (Bache \& Wickham, 2014), passport (Visel, 2020), purrr (Henry \& Wickham, 2020), pwr (Champely, 2020), readxl (Wickham \& Bryan, 2019), scales

\footnotetext{
3 "RMPE = recommended minimum effect size representing a 'practically' significant effect for social science data" (Ferguson, 2009, p. 533).
} 
(Wickham \& Seidel, 2020), see (Lüdecke et al., 2021), and tidyverse (Wickham et al., 2019). PDF data were extracted using Tabula (Aristarán et al., 2012). All data and code are available on a public repository (Lane, 2021). 


\section{Results}

Descriptive statistics can be found in Supplementary Table 1 and correlation coefficients in Supplementary Figures 1 and 2.

Direct comparison with results in Kleck (2021)

Table 2 directly compares results between Kleck (2021) and the reproduction. In contrast to Kleck, Small Arms Survey analysis found a significant association between firearm availability and total suicides. For every additional firearm per 100 population, the total suicide rate significantly increased by $0.6 \%(p=0.006)$, whereas Kleck found a nonsignificant increase of $0.1 \%(p=0.618)$. Otherwise the results were consistent between the original study and reproduction. 
Table 2. Comparison of model results between Kleck (2021) and this replication; significant results at $p \leq$ 0.05 in bold

\begin{tabular}{|c|c|c|c|c|c|c|}
\hline & \multicolumn{2}{|l|}{ Total suicide } & \multicolumn{2}{|l|}{ Firearm suicide } & \multicolumn{2}{|c|}{ Non-firearm suicide } \\
\hline \multicolumn{7}{|c|}{ Firearms per 100 population (Small Arms Survey): global } \\
\hline & Original & Reproduction & Original & Reproduction & Original & Reproduction \\
\hline $\mathrm{B}$ & 0.001 & 0.006 & 0.026 & 0.035 & -0.003 & 0.001 \\
\hline $\mathrm{SE}_{\mathrm{b}}$ & 0.002 & 0.002 & 0.004 & 0.004 & 0.002 & 0.002 \\
\hline $\mathrm{t}$ & 0.636 & 2.782 & 6.68 & 9.387 & -1.67 & 0.364 \\
\hline $\mathrm{p}$ & 0.618 & 0.006 & $<0.001$ & $<0.001$ & 0.096 & 0.716 \\
\hline \multicolumn{7}{|c|}{ Proportion of Suicides committed with Guns (PSG): global } \\
\hline & Original & Reproduction & Original & Reproduction & Original & Reproduction \\
\hline $\mathrm{B}$ & 0.001 & 0.003 & 0.097 & 0.101 & -0.012 & -0.010 \\
\hline $\mathrm{SE}_{\mathrm{b}}$ & 0.005 & 0.005 & 0.007 & 0.007 & 0.005 & 0.005 \\
\hline t & 0.156 & 0.679 & 14.31 & 15.167 & -2.60 & -2.064 \\
\hline $\mathrm{p}$ & 0.876 & 0.498 & $<0.001$ & $<0.001$ & $\mathbf{0 . 0 1 0}$ & 0.040 \\
\hline \multicolumn{7}{|c|}{ Firearm ownership rates (Firearms in the European Union): European Union } \\
\hline & Original & Reproduction & Original & Reproduction & Original & Reproduction \\
\hline $\mathrm{B}$ & -0.009 & -0.006 & 0.221 & 0.237 & -0.023 & -0.020 \\
\hline $\mathrm{SE}_{\mathrm{b}}$ & 0.029 & 0.027 & 0.044 & 0.052 & 0.030 & 0.028 \\
\hline $\mathrm{t}$ & -0.299 & -0.203 & 4.97 & 4.573 & -0.76 & -0.718 \\
\hline $\mathrm{p}$ & 0.768 & 0.841 & $<0.001$ & $<0.001$ & 0.452 & 0.479 \\
\hline
\end{tabular}

\section{Transformed firearm rates and US analyses}

Associations between firearm availability and suicide rates are illustrated in the scatterplot in

Figure 1; scatterplots for all groups can be found in Supplementary Figure 1. Effect sizes are

illustrated in Figure 2, while a full table of results can be found in Supplementary Table 2. 


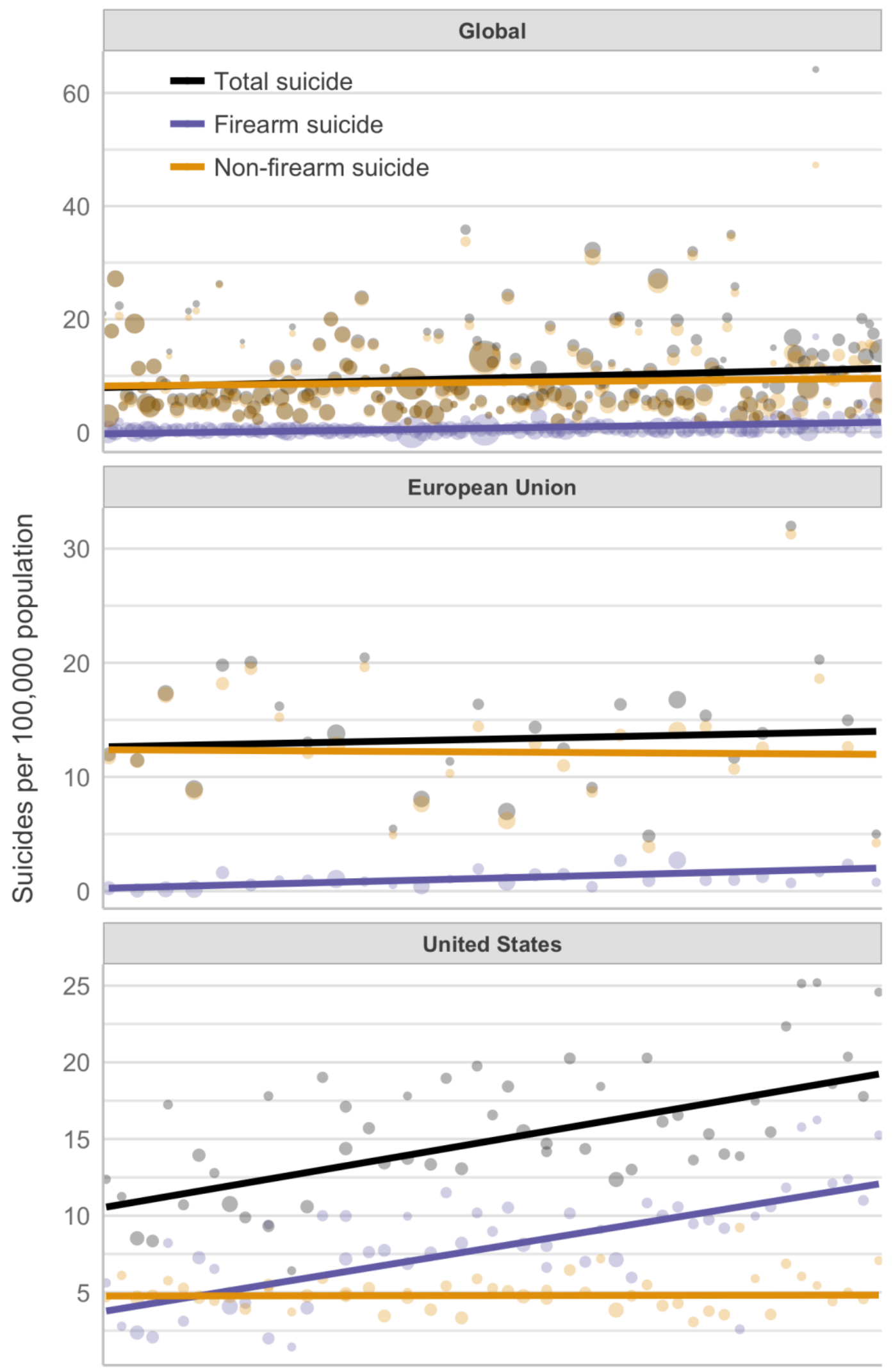

Firearms per 100 persons/ownership rate (ranked)

Figure 1. Scatterplot and fitted regression line, weighted by the population square root, of firearm availability and suicide rates 
Global

Results were consistent across transformations of firearm availability, only varying in terms of marginal significance/non-significance. As coefficients from the z-scored firearm rate provide the most meaningful scale of association, it is reported here. A standard deviation increase in firearm availability was associated with a $7.5 \%$ higher total suicide rate $(95 \% \mathrm{CI}$ : $2.2 \%$ to $12.7 \% ; p=0.006)$, though the effect size just met the minimum practical significance threshold $\left(r^{2}=0.04\right)$. It was also associated with a $43.0 \%$ higher firearm suicide rate $(95 \%$ CI: $34.0 \%$ to $52.1 \% ; p<0.001 ; r^{2}=0.30$ ), but no detectable association with the non-firearm suicide rate $(p=0.364)$.

Across stratifications, the positive association between firearm availability and firearm suicides was robust. However, the association between firearm availability and total suicides reversed with age: while positively associated in the youngest group (15-49 years), there was no detectable association in the middle age group (50-69 years) and an inverse association in the oldest group (70+ years) (this was only significant where firearm availability was ranked, but clearly negative with crude and z-scored firearm availability). Firearm availability was also negatively associated with non-firearm suicides in the oldest group.

\section{European Union}

In the EU, firearm availability was only significantly associated with firearm suicides, which was consistent across all demographic groups. This presents the same inconsistency identified in the Introduction, where firearm availability was only found to influence one component of suicide, but not the other component nor overall rates.

To check whether this was an issue with the EU firearm survey data, I re-analysed the EU using Small Arms Survey firearm data. The two firearm measures were significantly correlated $(p<0.001)$ with a Pearson's $r$ of 0.75 (similar to Kleck at $r=0.69$ ), meaning just 
over half the variance in one measure was explained by the other $\left(r^{2}=0.56\right)$. Nevertheless, there was no change in significance or direction of effects (see Supplementary Figures 3 and 4).

\section{United States}

US results were similar to global associations, though of greater magnitude: a standard deviation increase in firearm availability was associated with a $20.3 \%$ higher total suicide rate (95\% CI: $13.8 \%$ to $26.7 \% ; p<0.001)$. The $r^{2}$ was 0.45 , midway between a moderate and strong effect. Firearm suicides were $42.1 \%$ higher (95\% CI: $29.8 \%$ to $54.4 \%$; $p<0.001$ ) with a similar effect size magnitude $\left(r^{2}=0.49\right)$. Both associations are clearly visible in Figure 1. There was no detectable association with non-firearm suicide rates $(p=0.804)$.

For all subgroups, firearm availability was significantly associated with higher total and firearm suicide rates. However, there was substantial variation within non-firearm suicides, including an inverse association with non-firearm suicides in the older (50-69 and 70+ years) and Black demographic groups.

There was a significant positive association between firearms and non-firearm suicide within the Native American demographic group. However, these associations are unreliable due to large amounts of suppressed data due to low counts, a recurring problem for this group (Smith \& Kawachi, 2014). Total suicides were suppressed in 10 states and DC (20\%), firearm suicides in 24 states and DC (47\%), and non-firearm suicides in 23 states and DC (45\%). States where Native American suicide data were not suppressed had significantly higher firearm ownership rates $(p=0.018)$ and firearm suicides $(p=0.001)$, and were nonsignificantly higher for total and non-firearm suicides, as determined by a Mann-Whitney U test. This is illustrated in Supplementary Figure 5. 
Global: firearms per 100 residents and suicide rates
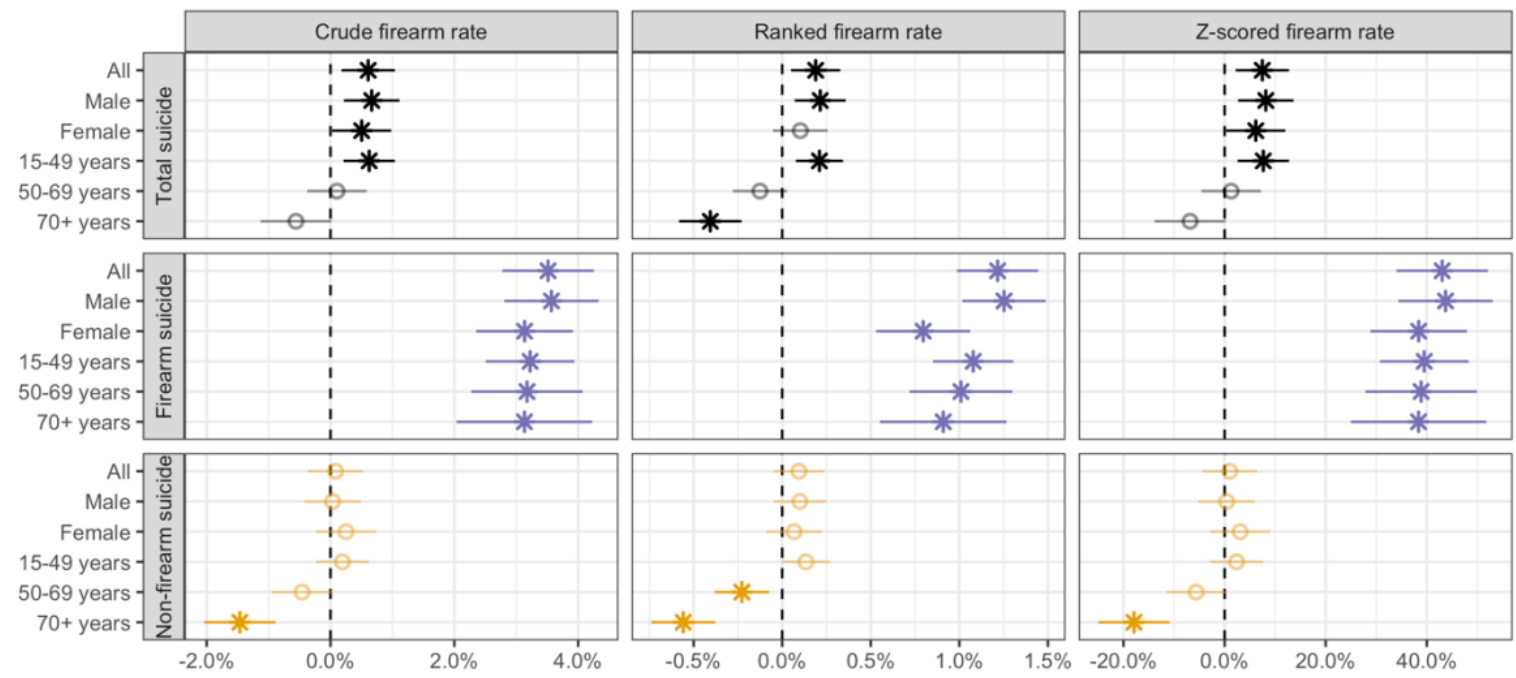

European Union: firearm ownership and suicide rates
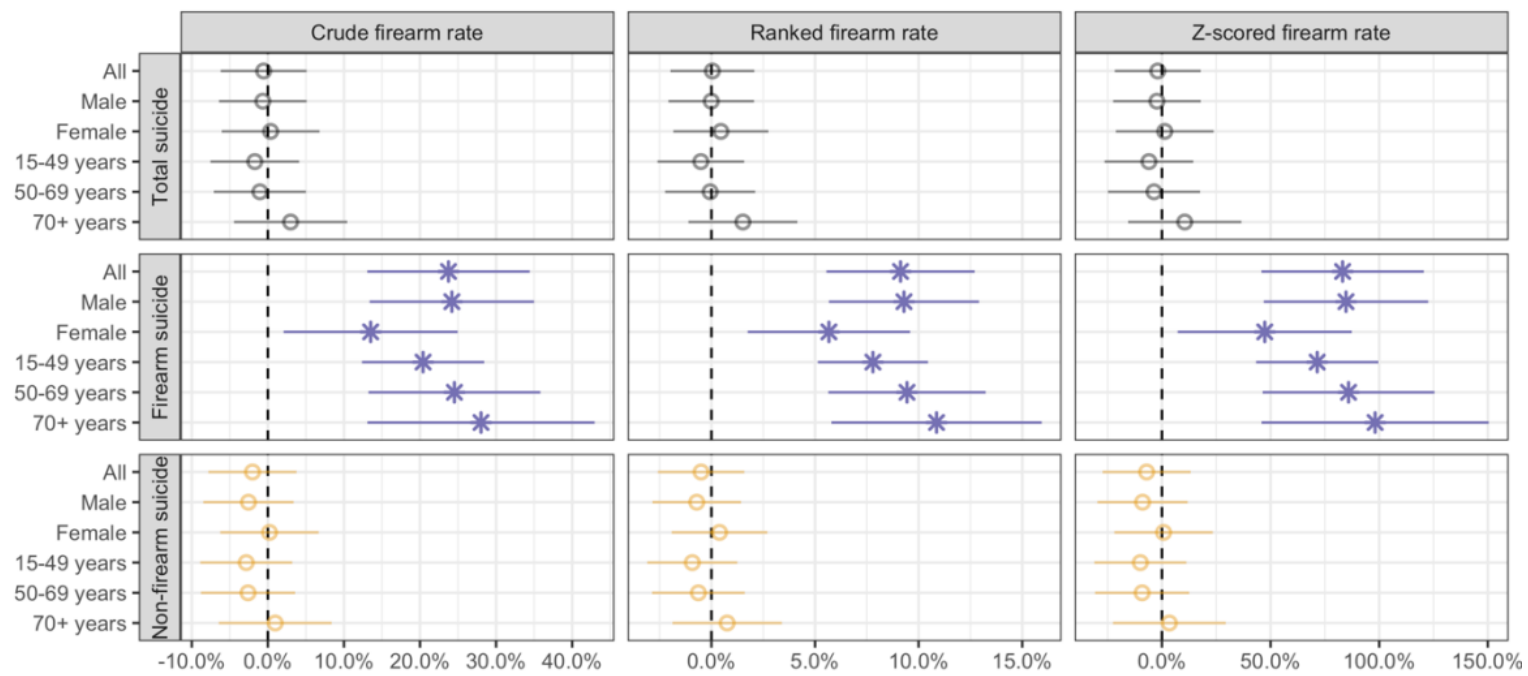

United States: firearm ownership and suicide rates
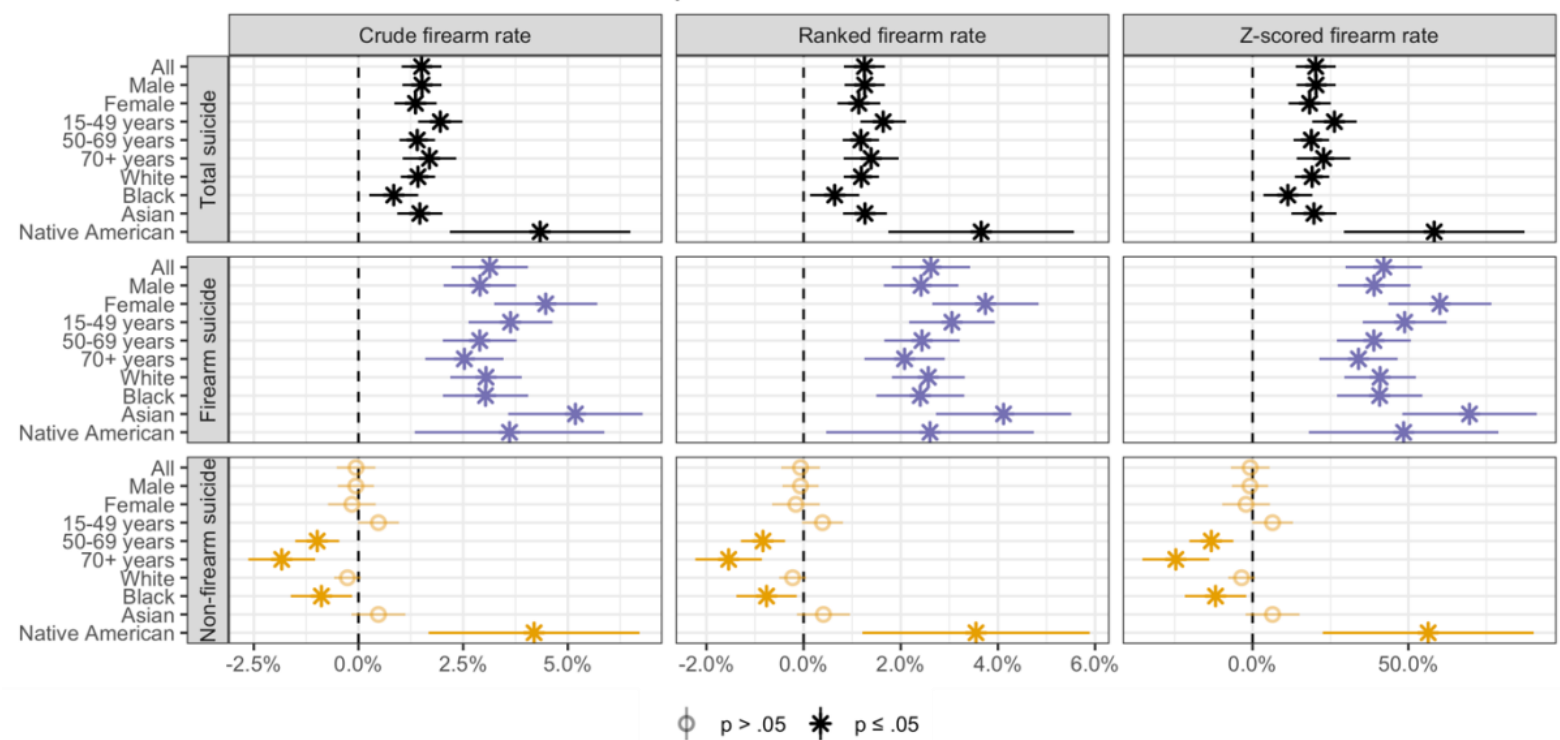

Figure 2. Direction, magnitude, and significance of associations between firearm availability and suicide rates 


\section{Discussion}

The main analysis in Kleck (2021), which used Small Arms Survey for firearm availability estimates, showed no association between firearm availability and suicide rates. I was unable to reproduce this result, finding instead a significant and positive association. It is not clear why, since the reproduction followed Kleck's approach precisely. The only real difference is the original had a sample of $n=194$ nation-states, whereas the reproduction had $n=203$, likely due to how firearm and suicide datasets were merged. Since Kleck did not include study materials or data, I am unable to investigate further, though it seems unlikely that nine data points would so dramatically change the results.

Results from Kleck's PSG and EU analyses, which showed no association between firearm availability and suicide rates, were reproduced. However, these analyses were unreliable: PSG is vulernable to spurious associations because of circularity in their models (National Research Council, 2005), while the EU analyses were underpowered and therefore vulernable to Type II Errors. The latter may explain why the reproduced EU analyses were internally inconsistent as in the original: firearm availability associated with firearm suicides but not total or non-firearm suicides. With 28 data points, the effect size would need to be $r=0.45$ (assuming $\alpha=0.05$ and $\beta=0.20$ ) to be detectable, which is unlikely in a region with generally low firearm ownership. This is contrast to US studies that found a significant association despite fewer data points (e.g., 9 census regions or 7 states in the northeast), but where guns are much more widely available and the association considerably stronger (Birckmayer \& Hemenway, 2001; Hemenway \& Miller, 2002; Miller et al., 2002a, 2002b, 2004). However, it is worth noting that the EU effects plot in Figure 2 shows the point estimate for total suicides is near zero. This could mean that, in the EU, firearm availability may very well have no or negligible influence on total suicide rates. There is also a non- 
significant negative association with non-firearm suicide rates, which could reflect method substitution. While limited statistical power necessitates a cautious interpretation, the EU may have population-level method substitution without a detectable effect on overall suicide rates.

This raises the question of whether the original study or the reproduction is more reliable . There are several factors that support the reproduction. First, the most reliable analyses (global with the Small Arms Survey and within the US), the results resolve the internal inconsistency found in Kleck (2021). Second, in line with Open Science practices, I archived my data and code on a public repository. Open Science practices are essential for improving the reliability of research because they enable anyone to reproduce results, audit methods, and identify errors (Chin et al., 2021; Ritchie, 2020), and also encourage researchers to take more care in compiling their work. Third, the reproduction and replication are consistent with existing reviews (Anglemyer et al., 2014; Miller et al., 2016; RAND Corporation, 2018). Lastly, as noted in the Introduction, Kleck's study shows signs of questionable research practices, specifically researcher degrees of freedom/p-hacking.

Effect sizes varied substantially between analyses; globally, firearm availability explained only $4 \%$ of the variance in suicide rates and $0 \%$ in the EU, but $45 \%$ in the US.

Correspondingly, firearms are widely available in the US but heavily restricted almost everywhere else on earth. The US may therefore provide a window into how expanding firearm availability would influence suicide rates. However, it may not offer a precise counterfactual since US gun culture is an important component of how firearm availability influences suicide rates (Ajdacic-Gross et al., 2008; Brown et al., 2006). The relative rarity of firearms in most other nations may not just limit their physical availability, but also their acceptance as a means of suicide. 
One surprising finding was that on a global scale, firearms were negatively associated with total suicides among older persons. Because the data are cross-sectional, they do not capture how firearm availability shapes populations over time. One explanation may be depletion of susceptibles (Stovitz et al., 2018): where firearms are more readily available, a higher proportion of individuals at-risk of suicide may commit suicide before reaching old age. This could make the surviving older population less prone to suicide than the population in general.

While there was minimal evidence of method substitution at a population level, there was evidence within some subgroups. Similar to Miller et al (2002a), firearms were negatively associated with non-firearm suicides among older persons. As above, this may be explained by depletion of susceptibles. However, the same was observed among Black Americans. This may be evidence of method substitution, though it is not clear why it would appear in this group. Social acceptability of suicide methods may play a role (Ajdacic-Gross et al., 2008). Previous work has found that a higher proportion of Black American suicide victims use violent methods, which was attributed to greater exposure to violence that makes violent suicide methods more socially acceptable (Stack \& Wasserman, 2005).

\section{Strengths and limitations}

To my knowledge, this reproduction and replication of Kleck (2021) uses the largest sample of nation-states to investigate the association between firearm availability and suicide $(n=$ 203). Aside from unreliable PSG and underpowered EU analyses, the findings are internally consistent and similar across regions and datasets, and, according to several literature reviews (Anglemyer et al., 2014; Miller et al., 2016; RAND Corporation, 2018), consistent with the evidence base. Results were robust across various transformations of firearm availability and 
stratifications, though there were some notable variations between age and ethnic groups. For transparency, data and code have been archived on a public repository.

There are some limitations. The data were cross-sectional, which did not allow tests of longitudinal effects such as depletion of susceptibles and changes in firearm availability. PSG analyses were unreliable, but were conducted for complete reproduction of the original study. Suppressed cells in the US suicide data, particularly among Native Americans, likely biased results. Stratified analyses assumed that variations in firearm availability within subgroups correspond to those in the population, which may not be the case (National Research Council, 2005). Two of the firearm rate estimates were based on survey data, which are subject to biased sampling or responses. 


\section{Conclusion}

This reproduction and replication suggests that the original findings of Kleck (2021) are unreliable and that its conclusion, that firearm availability does not influence suicide rates, is unjustified. Results based on the most robust methods did not reproduce, showing instead a significant and positive association between a nation's firearm availability and overall suicide rate. While other results showing no association were successfully reproduced, they were based on either unreliable or underpowered methods that Kleck himself had previously identified as "major problems". Additional analyses of US data bolstered suggested that as guns become more prevalent, the association with suicide rates grows stronger. While we must still exercise caution before definitively claiming that greater firearm availability increases suicide, this study demonstrates that, despite its claims, Kleck (2021) does not present evidence that firearms only influence how people commit suicide rather than how many. 


\section{Funding details}

This study received no funding. It was conducted in the author's spare time.

\section{Declaration of interest statement}

I declare no conflict of interests in conducting this study.

\section{Data availability statement}

All data and analytical code have been archived on a public repository:

https://doi.org/10.26180/14600337 


\section{References}

Ajdacic-Gross, V., Weiss, M. G., Ring, M., Hepp, U., Bopp, M., Gutzwiller, F., \& Rössler, W. (2008). Methods of suicide: International suicide patters derived from the WHO mortality database. Bulletin of the World Health Organization, 86(9), 726-732. https://doi.org/10.2471/BLT.07.043489

Anestis, M. D., \& Houtsma, C. (2018). The sssociation between gun wwnership and statewide overall suicide rates. Suicide and Life-Threatening Behavior, 48(2), 204217. https://doi.org/10.1111/sltb.12346

Anglemyer, A., Horvath, T., \& Rutherford, G. (2014). The accessibility of firearms and risk for suicide and homicide victimization among household members: A systematic review and meta-analysis. Annals of Internal Medicine, 160(2), 101-110. https://doi.org/10.7326/M13-1301

Aristarán, M., Tigas, M., Merrill, J. B., Das, J., Frackman, D., \& Swicegood, T. (2012). Tabula. https://tabula.technology

Bache, S. M., \& Wickham, H. (2014). magrittr: A Forward-Pipe Operator for $R$.

Birckmayer, J., \& Hemenway, D. (2001). Suicide and Firearm Prevalence: Are Youth Disproportionately Affected? Suicide and Life-Threatening Behavior, 31(3), 303-310. https://doi.org/10.1521/suli.31.3.303.24243

Bishop, D. (2019). Rein in the four horsemen of irreproducibility. Nature, 568(7753), 435435. https://doi.org/10.1038/d41586-019-01307-2

Briggs, J. T., \& Tabarrok, A. (2014). Firearms and suicides in US states. International Review of Law and Economics, 37, 180-188.

https://doi.org/10.1016/j.irle.2013.10.004 
Brown, J. A., McDonough, P., Mustard, C. A., \& Shannon, H. S. (2006). Healthcare use before and after a workplace injury in British Columbia, Canada. Occupational and Environmental Medicine, 63(6), 396-403. https://doi.org/10.1136/oem.2005.022707

Cai, Z., Junus, A., Chang, Q., \& Yip, P. S. F. (2022). The lethality of suicide methods: A systematic review and meta-analysis. Journal of Affective Disorders, 300, 121-129. https://doi.org/10.1016/j.jad.2021.12.054

Centers for Disease Control and Prevention. (2021). Wide-Ranging Online Data for Epidemiological Research (WONDER). National Center for Health Statistics. http://wonder.cdc.gov/ucd-icd10.html

Champely, S. (2020). Pwr (1.3-0) [R]. https://CRAN.R-project.org/package=pwr

Chin, J. M., Pickett, J. T., Vazire, S., \& Holcombe, A. O. (2021). Questionable Research Practices and Open Science in Quantitative Criminology. Journal of Quantitative Criminology. https://doi.org/10.1007/s10940-021-09525-6

Crowder, M. K., \& Kemmelmeier, M. (2014). Untreated depression predicts higher suicide rates in U.S. honor cultures. Journal of Cross-Cultural Psychology, 45(7), 11451161. https://doi.org/10.1177/0022022114534915

Duggan, M. (1999). Guns and Suicide. In J. Ludwig \& P. J. Cook (Eds.), Evaluating Gun Policy: Effects on Crime and Violence (pp. 41-73). Brookings Institution Press.

Elnour, A. A., \& Harrison, J. (2008). Lethality of suicide methods. Injury Prevention, 14(1), 39-45. https://doi.org/10.1136/ip.2007.016246

European Commission. (2013). Firearms in the European Union (No. 383; Flash Eurobarometer 383). European Union. https://europa.eu/eurobarometer/surveys/detail/1125 
Ferguson, C. J. (2009). An effect size primer: A guide for clinicians and researchers. Professional Psychology: Research and Practice, 40(5), 532-538. https://doi.org/10.1037/a0015808

Firke, S. (2020). janitor: Simple Tools for Examining and Cleaning Dirty Data.

Gelman, A., Hill, J., \& Vehtari, A. (2020). Regression and Other Stories. Cambridge University Press. https://users.aalto.fi/ ave/ROS.pdf

Global Burden of Disease Collaborative Network. (2020). Global Burden of Disease Study 2019 (GBD 2019) Results. Institute for Health Metrics and Evaluation (IHME). http://ghdx.healthdata.org/gbd-results-tool

Hamilton, D., \& Kposowa, A. (2015). Firearms and Violent Death in the United States: Gun Ownership, Gun Control and Mortality Rates in 16 States, 2005-2009. British Journal of Education, Society \& Behavioural Science, 7(2), 84-98. https://doi.org/10.9734/BJESBS/2015/16126

Hemenway, D., \& Miller, M. (2002). Association of rates of household handgun ownership, lifetime major depression, and serious suicidal thoughts with rates of suicide across US census regions. Injury Prevention, 8(4), 313-316. https://doi.org/10.1136/ip.8.4.313

Henry, L., \& Wickham, H. (2020). purrr: Functional Programming Tools (0.3.4) [R]. https://CRAN.R-project.org/package=purrr

Kalesan, B., Villarreal, M. D., Keyes, K. M., \& Galea, S. (2016). Gun ownership and social gun culture. Injury Prevention, 22(3), 216-220. https://doi.org/10.1136/injuryprev2015-041586

Karp, A. (2018). Estimating Global Civilian-Held Firearms Numbers. Small Arms Survey. http://www.smallarmssurvey.org/fileadmin/docs/T-Briefing-Papers/SAS-BP-CivilianFirearms-Numbers.pdf 
Kassambara, A. (2020). ggpubr: 'ggplot2' Based Publication Ready Plots (0.4.0) [Computer software]. https://cran.r-project.org/package=ggpubr

Killias, M. (1993). International correlations between gun ownership and rates of homicide and suicide. Canadian Medical Association Journal, 148(10), 1721-1725.

Kleck, G. (1991). Point Blank: Guns and Violence in America. Routledge.

Kleck, G. (2018). The Effect of Firearms on Suicide. In J. Carlson, K. A. Goss, \& H. Shapira (Eds.), Gun Studies: Interdisciplinary Approaches to Politics, Policy, and Practice (1st ed., pp. 309-329). Routledge. https://doi.org/10.4324/9781315696485

Kleck, G. (2019). Macro-level research on the effect of firearms prevalence on suicide rates: A systematic review and new evidence. Social Science Quarterly, 100(3), 936-950. https://doi.org/10.1111/ssqu.12602

Kleck, G. (2021). The cross-national association of gun ownership rates and suicide rates: An analysis of 194 nations. Archives of Suicide Research, 1-9. https://doi.org/10.1080/13811118.2021.1922110

Kleck, G., \& Patterson, E. B. (1993). The impact of gun control and gun ownership levels on violence rates. Journal of Quantitative Criminology, 9(3), 249-287. https://doi.org/10.1007/BF01064462

Kposowa, A. J. (2013). Association of suicide rates, gun ownership, conservatism and individual suicide risk. Social Psychiatry and Psychiatric Epidemiology, 48(9), 14671479. https://doi.org/10.1007/s00127-013-0664-4

Lane, T. J. (2021). Associations between firearms and suicide: Data and code [Repository]. Bridges. https://doi.org/10.26180/14600337

Lüdecke, D., Patil, I., Ben-Shacha, M., Wiernik, B. M., Waggoner, P., \& Makowski, D. (2021). see: Visualisation Toolbox for ‘easystats' and Extra Geoms, Themes, and 
Color Palettes for 'ggplot2'. Journal of Open Source Software, 6(64), 3393. https://doi.org/10.21105/joss.03393

Miller, M., Azrael, D., \& Hemenway, D. (2002a). Household firearm ownership and suicide rates in the United States. Epidemiology, 13(5), 517-524. https://doi.org/10.1097/00001648-200209000-00006

Miller, M., Azrael, D., \& Hemenway, D. (2002b). Firearm availability and unintentional firearm deaths, suicide, and homicide among 5-14 Year Olds: Journal of Trauma and Acute Care Surgery, 52(2), 267-275. https://doi.org/10.1097/00005373-20020200000011

Miller, M., Barber, C., White, R. A., \& Azrael, D. (2013). Firearms and suicide in the United States: Is risk independent of underlying suicidal behavior? American Journal of Epidemiology, 178(6), 946-955. https://doi.org/10.1093/aje/kwt197

Miller, M., Hemenway, D., \& Azrael, D. (2004). Firearms and suicide in the Northeast. The Journal of Trauma: Injury, Infection, and Critical Care, 57(3), 626-632. https://doi.org/10.1097/01.TA.0000093367.07960.E4

Miller, M., Swanson, S. A., \& Azrael, D. (2016). Are we missing something pertinent? A bias analysis of unmeasured confounding in the firearm-suicide literature. Epidemiologic Reviews, 38(1), 62-69. https://doi.org/10.1093/epirev/mxv011

Moher, D., Liberati, A., Tetzlaff, J., Altman, D. G., \& The PRISMA Group. (2009). Preferred Reporting Items for Systematic Reviews and Meta-Analyses: The PRISMA Statement. PLoS Medicine, 6(7), e100097. https://doi.org/10.1371/ journal.pmed.1000097

National Research Council. (2005). Firearms and Violence: A Critical Review (p. 10881). National Academies Press. https://doi.org/10.17226/10881 
Opoliner, A., Azrael, D., Barber, C., Fitzmaurice, G., \& Miller, M. (2014). Explaining geographic patterns of suicide in the US: The role of firearms and antidepressants. Injury Epidemiology, 1(1), 6. https://doi.org/10.1186/2197-1714-1-6

Phillips, J. A. (2013). Factors associated with temporal and spatial patterns in suicide rates across U.S. States, 1976-2000. Demography, 50(2), 591-614. https://doi.org/10.1007/s13524-012-0176-y

R Core Team. (2021). R: A language and environment for statistical computing (4.1) [R]. R Foundation for Statistical Computing. https://www.r-project.org/

RAND Corporation. (2018). The Relationship Between Firearm Availability and Suicide. https://www.rand.org/research/gun-policy/analysis/essays/firearm-availabilitysuicide.html

Reisch, T., Steffen, T., Habenstein, A., \& Tschacher, W. (2013). Change in Suicide Rates in Switzerland Before and After Firearm Restriction Resulting From the 2003 "Army XXI” Reform. American Journal of Psychiatry, 170(9), 977-984. https://doi.org/10.1176/appi.ajp.2013.12091256

Ritchie, S. (2020). Science Fictions: Exposing Fraud, Bias, Negligence and Hype in Science (Kindle). Penguin Random House UK.

Robinson, D., \& Hayes, A. (2020). broom: Convert Statistical Analysis Objects into Tidy Tibbles.

RStudio Team. (2020). RStudio: Integrated Development for $R$ (1.4.904) [R]. RStudio, Inc. https://www.rstudio.com

Shenassa, E. D., Catlin, S. N., \& Buka. (2003). Lethality of firearms relative to other suicide methods: A population based study. Journal of Epidemiology \& Community Health, 57(2), 120-124. https://doi.org/10.1136/jech.57.2.120 
Simmons, J. P., Nelson, L. D., \& Simonsohn, U. (2011). False-positive psychology:

Undisclosed flexibility in data collection and analysis allows presenting anything as significant. Psychological Science, 22(11), 1359-1366.

https://doi.org/10.1177/0956797611417632

Smith, N. D. L., \& Kawachi, I. (2014). State-level social capital and suicide mortality in the 50 U.S. states. Social Science \& Medicine, 120, 269-277. https://doi.org/10.1016/j.socscimed.2014.09.007

Stack, S., \& Wasserman, I. (2005). Race and method of suicide: Culture and opportunity. Archives of Suicide Research, 9(1), 57-68. https://doi.org/10.1080/13811110590512949

Stovitz, S. D., Banack, H. R., \& Kaufman, J. S. (2018). 'Depletion of the susceptibles' taught through a story, a table and basic arithmetic. BMJ Evidence-Based Medicine, 23(5), 199-199. https://doi.org/10.1136/bmjebm-2018-110972

Visel, E. (2020). passport: Travel Smoothly Between Country Name and Code Formats (0.3.0) [Computer software]. https://CRAN.R-project.org/package=passport Wickham, H., Averick, M., Bryan, J., Chang, W., McGowan, L., François, R., Grolemund, G., Hayes, A., Henry, L., Hester, J., Kuhn, M., Pedersen, T., Miller, E., Bache, S., Müller, K., Ooms, J., Robinson, D., Seidel, D., Spinu, V., ... Yutani, H. (2019). Welcome to the Tidyverse. Journal of Open Source Software, 4(43), 1686. https://doi.org/10.21105/joss.01686

Wickham, H., \& Bryan, J. (2019). readxl: Read Excel Files. https://cran.rproject.org/package=readxl

Wickham, H., \& Seidel, D. (2020). scales: Scale Functions for Visualization (1.1.1) [Computer software]. https://cran.r-project.org/package=scales 


\section{Supplementary figures}

\section{Pearson correlations}

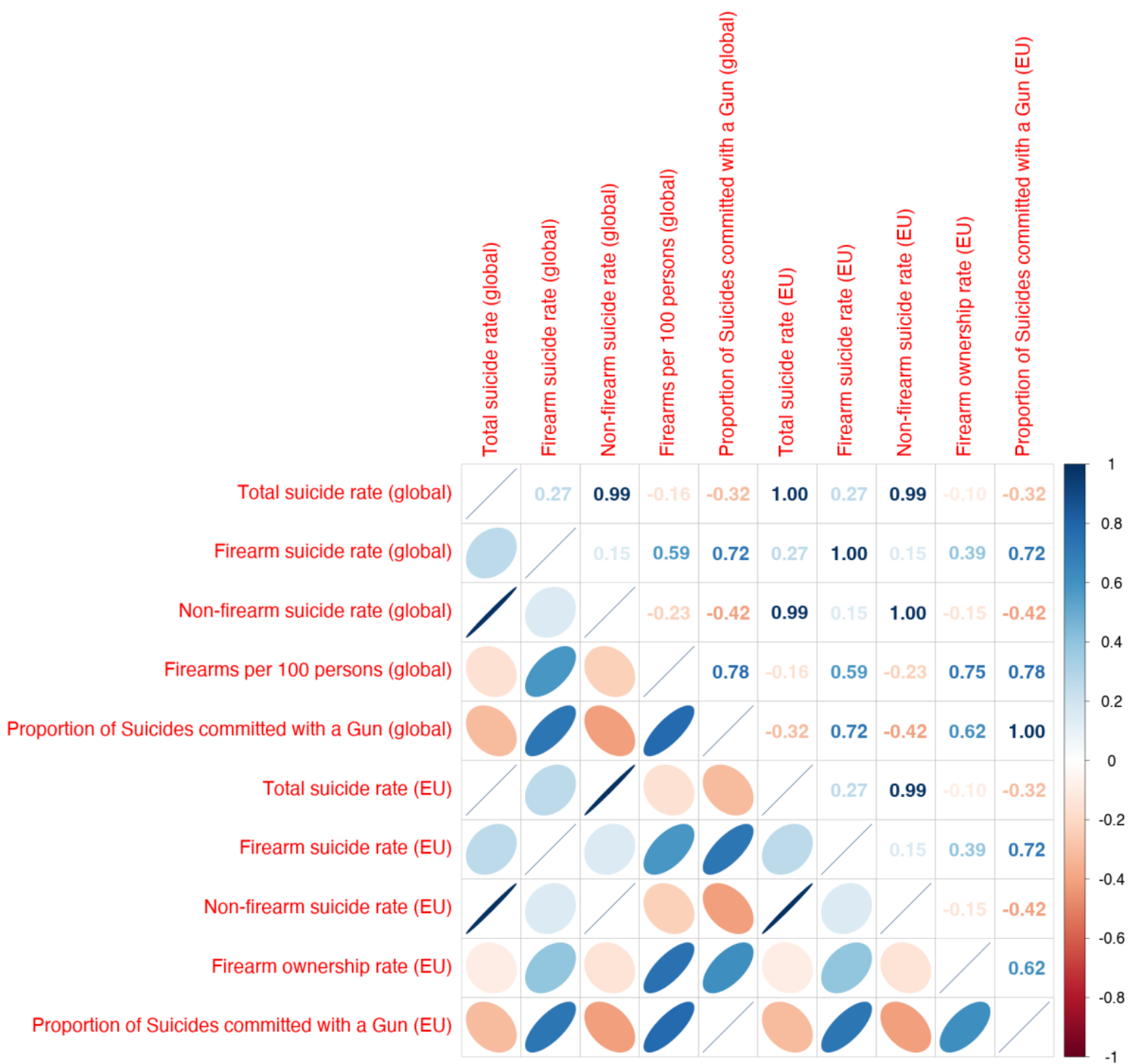

Supplementary figure 1. Pearson correlations across variables used in Kleck (2021) 


\section{Kendall correlations}

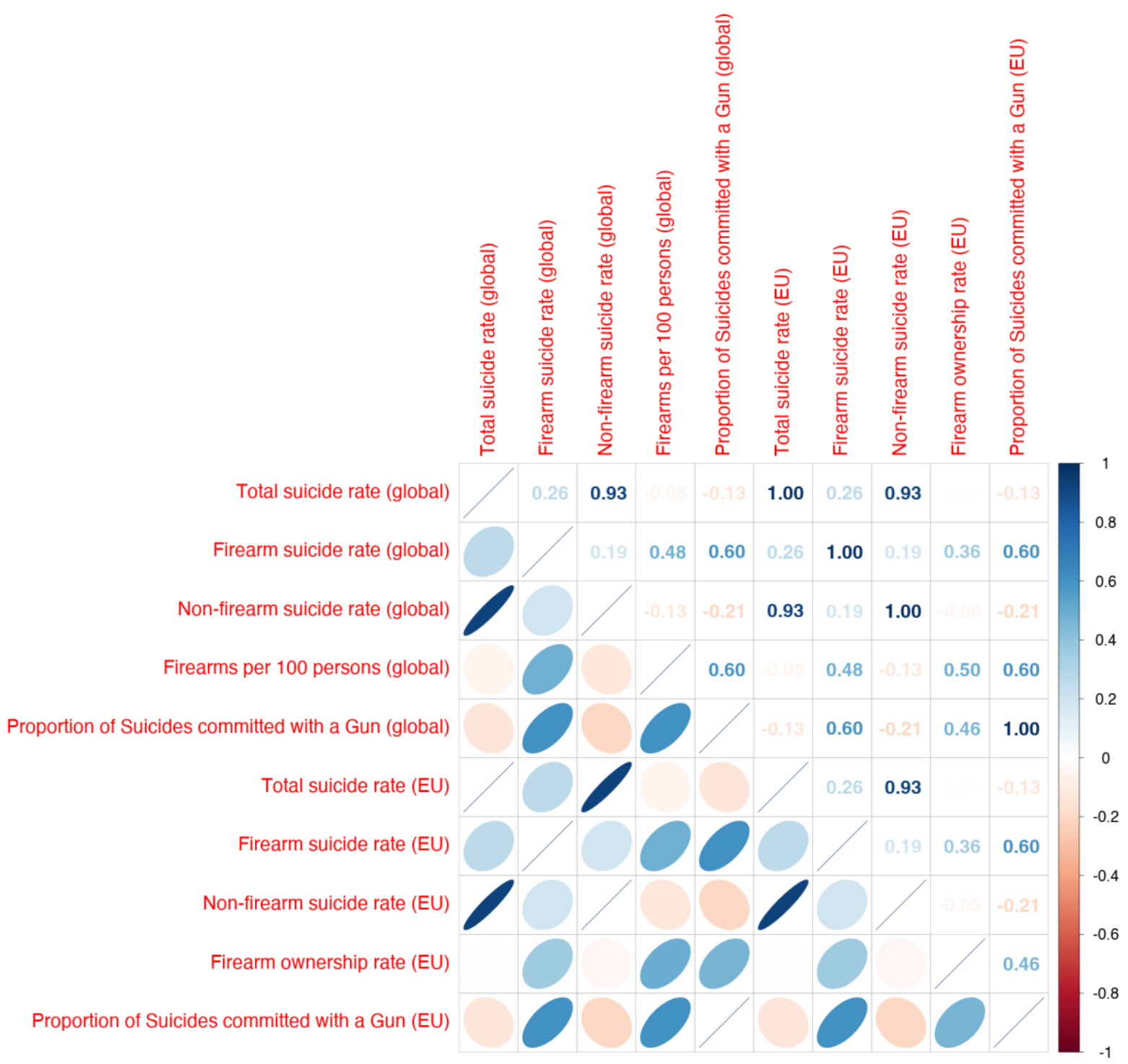

Supplementary figure 2. Kendall correlations across variables used in Kleck (2021); Kendall correlations are more appropriate given the non-parametric nature and small counts of some data 
Global
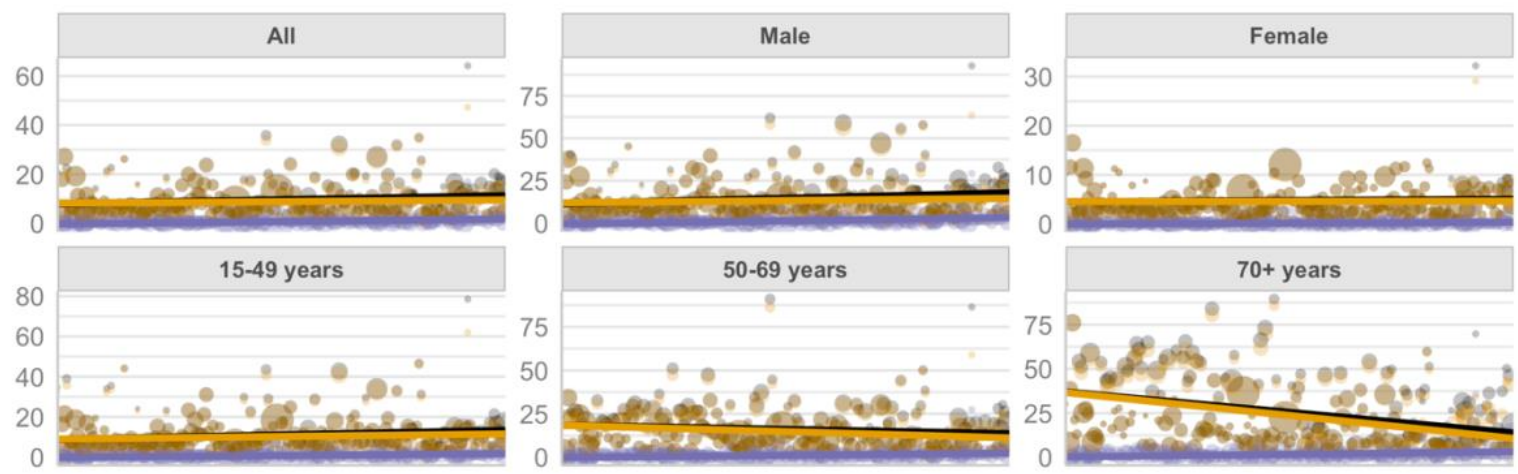

Firearms per 100 population (ranked)

European Union
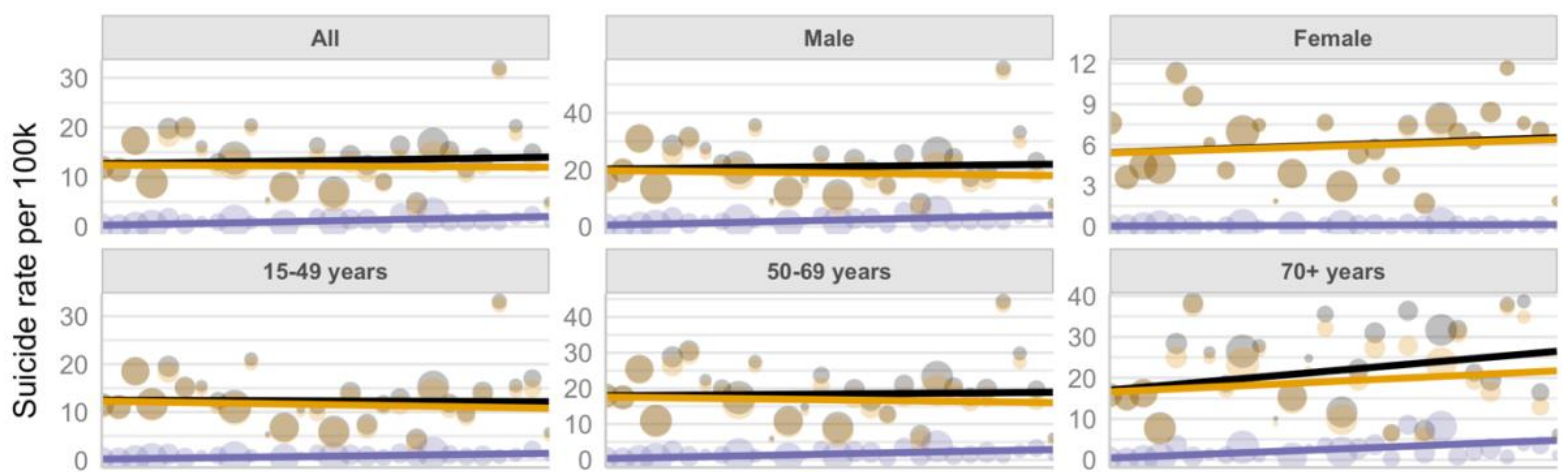

Firearm ownership rate (ranked)

United States
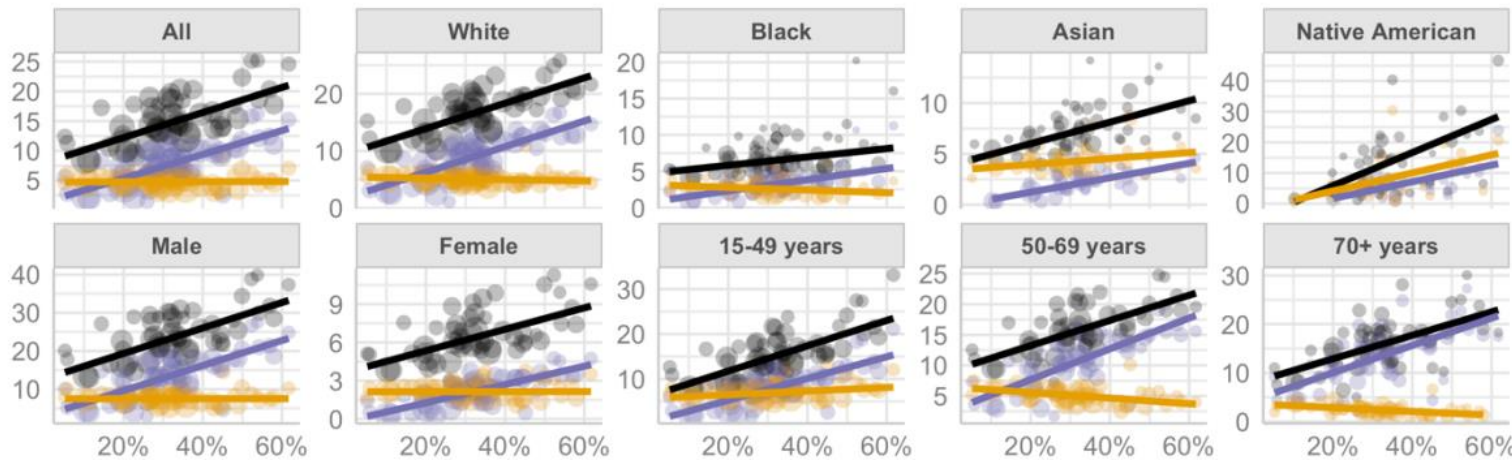

Firearm ownership rate

Method — Total suicide - Firearm suicide - Non-firearm suicide

Supplementary figure 3. Scatterplot and fitted regression line, weighted by the population square root, of firearm availability and suicide rates 


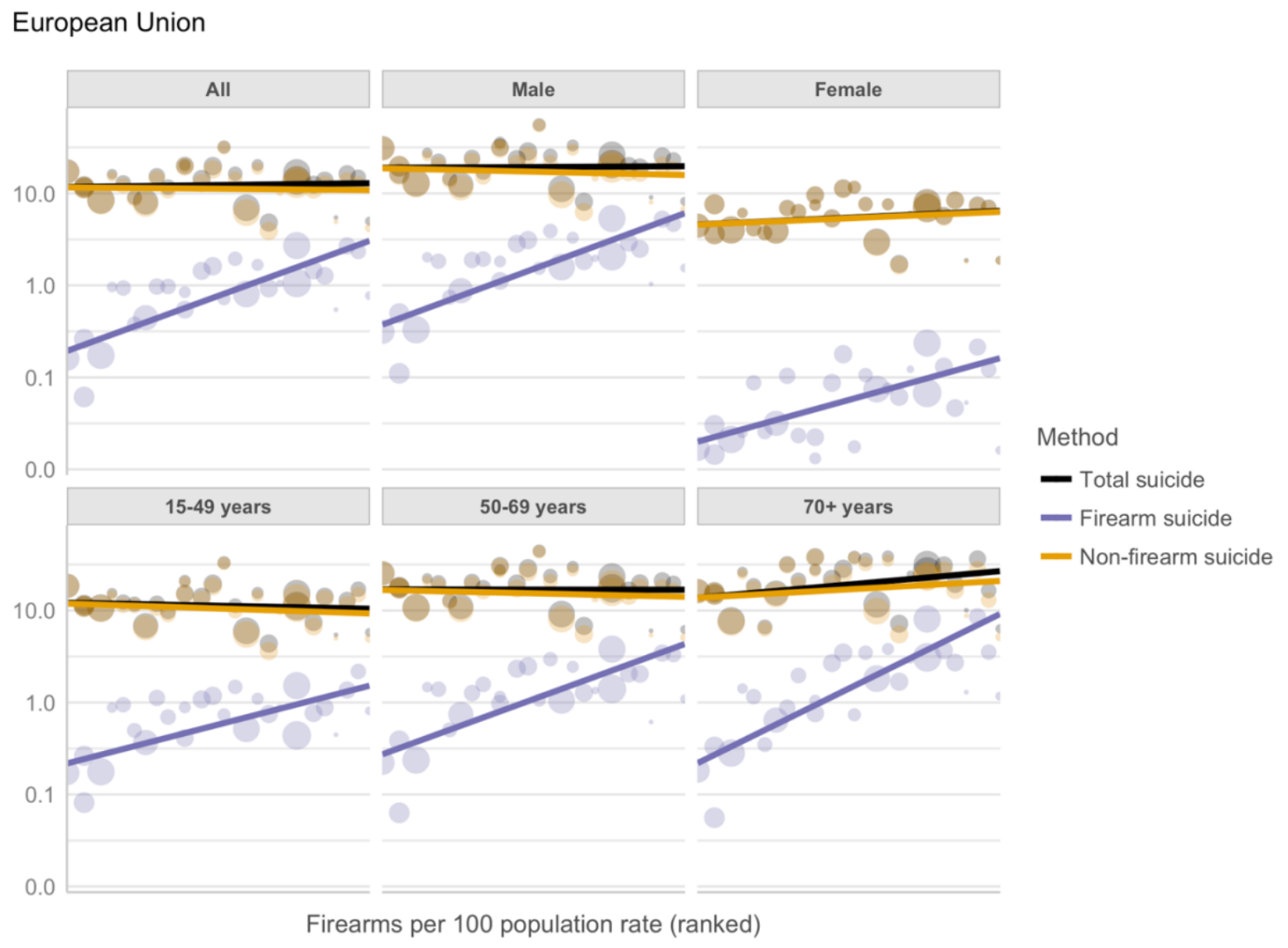

Supplementary figure 4. Scatterplot and fitted regression line, weighted by the population square root, of firearm and suicide rates in the European Union using Small Arms Survey data on firearms per 100 persons 
European Union: firerms per 100 population and suicide rates
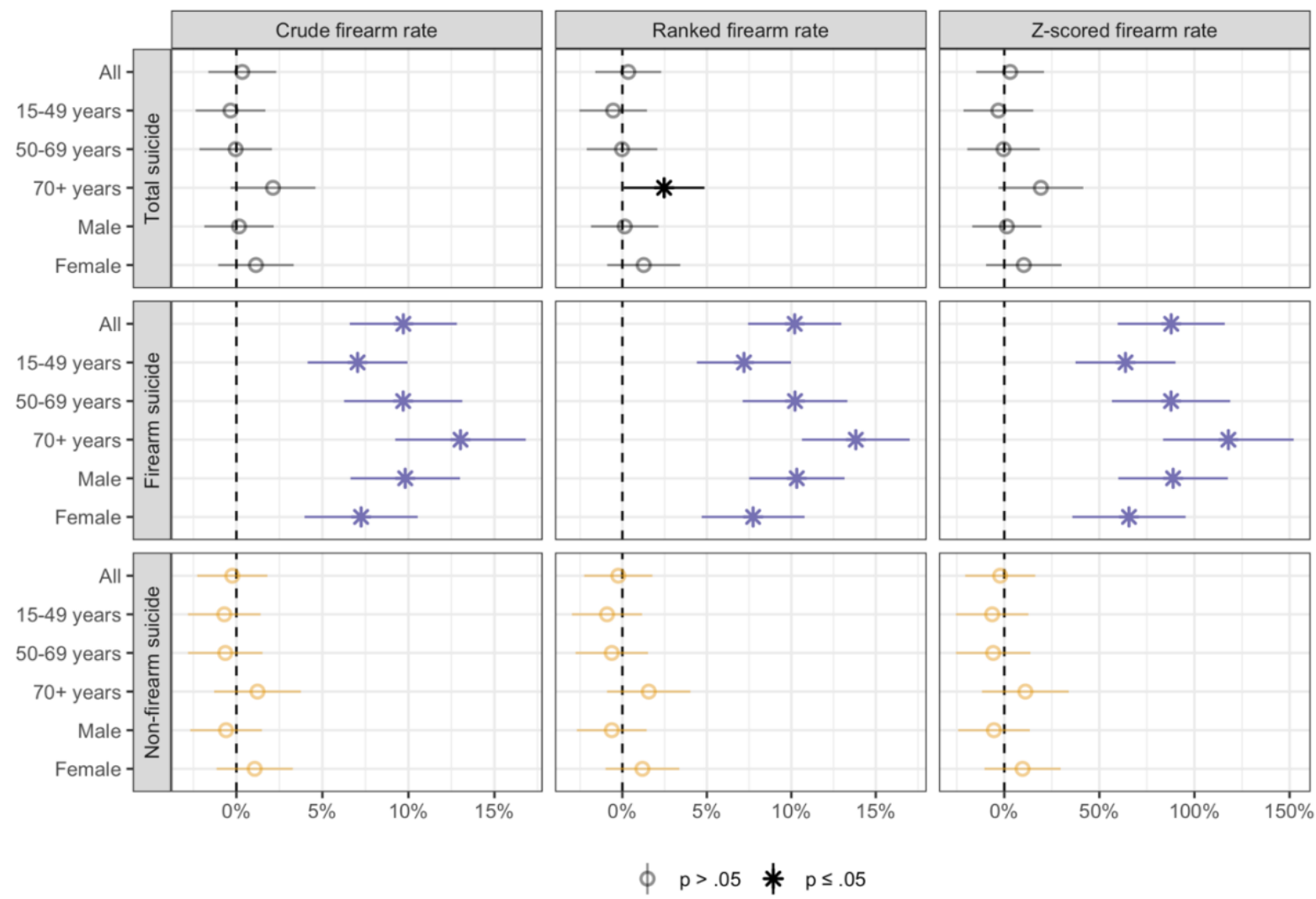

$\phi p>.05$ * $p \leq .05$

Supplementary figure 5. Strength of association between firearm and suicide rates in the European Union using Small Arms Survey data on firearms per 100 persons 

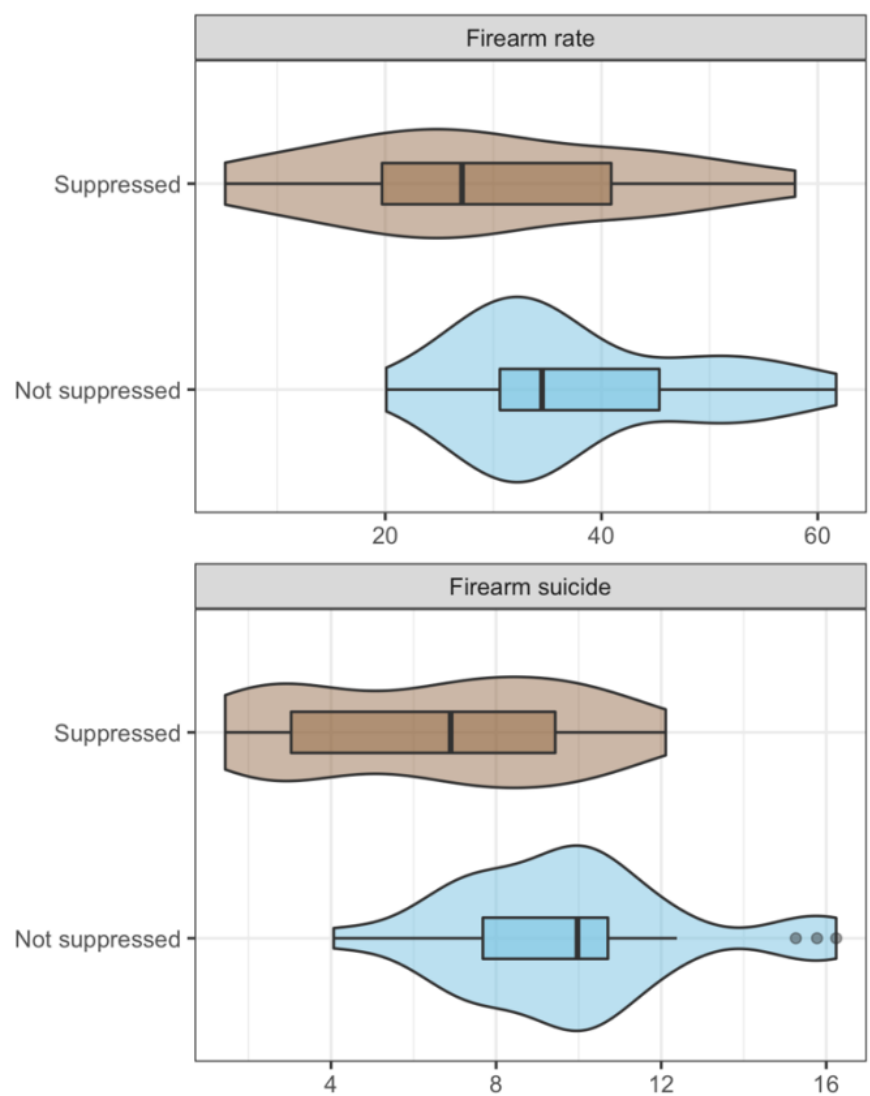

Suicide rate per $100 \mathrm{k} / \mathrm{household} \mathrm{firearm} \mathrm{ownership} \mathrm{\%}$
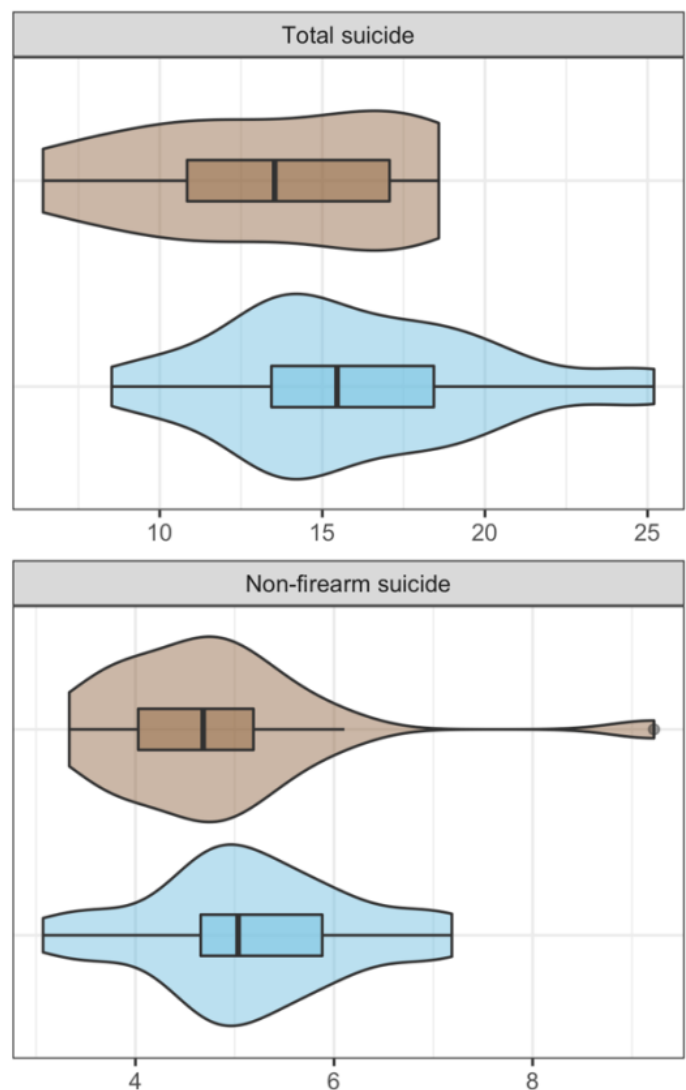

Supplementary figure 6. Comparison of population-level firearm and suicide rates in US states and DC based on whether Native American suicide data from CDC WONDER were suppressed 